\title{
dSTIM- and Ral/Exocyst-Mediated Synaptic Release from Pupal Dopaminergic Neurons Sustains Drosophila Flight
}

\author{
Shlesha Richhariya," Siddharth Jayakumar," Sanjay Kumar Sukumar, and ${ }^{\circledR}$ Gaiti Hasan
}

https://doi.org/10.1523/ENEURO.0455-17.2018

National Centre for Biological Sciences, TIFR, Bangalore 560065, India

\begin{abstract}
Manifestation of appropriate behavior in adult animals requires developmental mechanisms that help in the formation of correctly wired neural circuits. Flight circuit development in Drosophila requires store-operated calcium entry (SOCE) through the STIM/Orai pathway. SOCE-associated flight deficits in adult Drosophila derive extensively from regulation of gene expression in pupal neurons, and one such SOCE-regulated gene encodes the small GTPase Ral. The cellular mechanism by which Ral helps in maturation of the flight circuit was not understood. Here, we show that knockdown of components of a Ral effector, the exocyst complex, in pupal neurons also leads to reduced flight bout durations, and this phenotype derives primarily from dopaminergic neurons. Importantly, synaptic release from pupal dopaminergic neurons is abrogated upon knockdown of dSTIM, Ral, or exocyst components. Ral overexpression restores the diminished synaptic release of dStim knockdown neurons as well as flight deficits associated with dSTIM knockdown in dopaminergic neurons. These results identify Ral-mediated vesicular release as an effector mechanism of neuronal SOCE in pupal dopaminergic neurons with functional consequences on flight behavior.
\end{abstract}

Key words: Exo84; Neural Circuit; SOCE; Synaptic Maturation

\section{Significance Statement}

Appropriate wiring of neuronal circuits during development is essential for adult behavior, and cellular mechanisms such as calcium signaling orchestrate the pattern and strength of such neuronal connections to a significant extent. In Drosophila, flight behavior impacts multiple aspects of life. Calcium, especially through the store-operated calcium entry (SOCE) pathway, regulates gene expression during flight circuit maturation. Ral encodes a small GTPase and is one such SOCE-regulated gene required for Drosophila flight. In this paper, we show that SOCE-related loss of flight is determined to a significant extent by Ral and the exocyst complex-driven synaptic vesicle release in pupal dopaminergic neurons. Thus, SOCEregulated release of dopamine ensures correct wiring of the flight circuit in Drosophila.

\section{Introduction}

The coordinated development and maturation of neuronal circuits is essential for ensuring appropriate circuit function underlying adult behavior. Neural circuits develop and reach functional maturity through a complex process that begins with genetically encoded programs

\footnotetext{
Received December 28, 2017; accepted May 7, 2018; First published May 22, 2018.

The authors declare no competing interests

Author contributions: SR, SJ, and GH designed research; SR, SJ, and SKS performed research; SR, SJ, and GH wrote the paper.

This study was supported by grants from National Center for Biological Sciences, Tata Institute for Fundamental Research, to G.H. S.R. and S.J were supported by fellowships from National Center for Biological Sciences and Council of Scientific and Industrial Research, respectively.
}

${ }^{*}$ S.R. and S.J. contributed equally to this paper.

S. Richhariya's current address is Howard Hughes Medical Institute, National Center for Behavioral Genomics, Dept. of Biology, Brandeis University, Waltham, MA 02454.

Siddharth Jayakumar's current address is Dept. of Molecular \& Cellular Biology, Harvard University, MA 02138.

Acknowledgments: We thank Gero Miesenböck, Mark Wu, and Boris Egger for fly strains. We thank the Central Imaging and Flow Facility at NCBS for the use of its microscopes. Flies from the Vienna Drosophila RNAi Center (VDRC) 
for neural cell specification and is followed by neurotransmitter fate determination, axonal growth and path finding, synapse formation, and synapse maturation (Lohmann, 2009; Blankenship and Feller, 2010). Based on the context, various calcium signaling mechanisms influence circuit development (Lohmann, 2009; Rosenberg and Spitzer, 2011), including store-operated calcium entry (SOCE) through the STIM/Orai pathway (Prakriya and Lewis, 2015). Although STIM and Orai are expressed at multiple stages (Majewski and Kuznicki, 2015), their precise role in neural development and circuit formation needs better understanding.

In the holometabolous insect Drosophila, the nervous system, like all other organs, undergoes metamorphosis during pupal stages to attain the adult form from the distinct larval form (Truman, 1990). Most neurogenesis is accomplished in the embryonic and larval stages followed by remodeling of existing neurons during pupal stages in tune with adult functions (Truman and Bate, 1988; Tissot and Stocker, 2000; Consoulas et al., 2002). Interestingly, attenuation of STIM/Orai-mediated SOCE in pupal neurons leads to either absent or reduced flight bout durations (Agrawal et al., 2010; Pathak et al., 2015; Richhariya et al., 2017), supporting a role for SOCE during flight circuit maturation in Drosophila.

In non-excitable cells, SOCE regulates cellular responses by changes in gene expression (Feske, 2007). Indeed, SOCE-regulated expression of the dopamine-synthesizing enzyme tyrosine hydroxylase has previously been demonstrated in Drosophila pupal neurons (Pathak et al., 2015). In mouse neural progenitor cells as well, SOCE drives gene expression (Somasundaram et al., 2014). In a screen to identify SOCE-regulated genes in Drosophila pupal neurons, a small GTPase, Ral, was identified as a regulator of flight (Richhariya et al., 2017).

Mammalian RalA has several roles, many of which are exocyst linked, while some are not (Gentry et al., 2014). RalA regulates the releasable pool of synaptic vesicles in mammalian neurons (Polzin et al., 2002), and both RalA and RaIB mediate GTP-dependent exocytosis from neuroendocrine PC-12 cells (Wang et al., 2004; Li et al., 2007). In Drosophila, Ral-dependent exocyst function supports membrane addition in muscle cells (Teodoro et al., 2013), and similarly, in mouse cortical neurons, it supports neurite extension (Lalli and Hall, 2005). However, dendritic and axonal arborization patterns of central dopaminergic neurons implicated in Drosophila flight appear normal on attenuation of SOCE (Pathak et al., 2015).

Here we have investigated an alternate exocystdependent cellular mechanism by which SOCE-regulated Ral expression could help in maturation of the Drosophila

\footnotetext{
and the Bloomington Drosophila Stock Center (National Institutes of Health P400D018537) were used in this study.

Correspondence should be addressed to Gaiti Hasan, National Centre for Biological Sciences, TIFR, Bellary Road, Bangalore 560065, India. Email: gaiti@ncbs.res.in. https://doi.org/10.1523/ENEURO.0455-17.2018

Copyright (C) 2018 Richhariya et al.

This is an open-access article distributed under the terms of the Creative Commons Attribution 4.0 International license, which permits unrestricted use, distribution and reproduction in any medium provided that the original work is properly attributed.
}

flight circuit during pupal development. We show that release of synaptic vesicles in maturing pupal neurons requires the SOCE component dSTIM as well as Ral-exocyst function. We propose that dSTIM- and Ral/exocystdependent vesicular release is required for synaptic maturation of the flight circuit.

\section{Materials and Methods}

\section{Fly rearing and stocks}

Drosophila strains were grown on cornmeal medium supplemented with yeast. For all experiments, flies of either sex were used. For all experiments, unless stated otherwise, egg laying was performed at $25^{\circ} \mathrm{C}$. Late third instar larvae were moved to $29^{\circ} \mathrm{C}$ to increase the expression of GAL4 and were maintained at the elevated temperature until adults eclosed, after which they were moved back to $25^{\circ} \mathrm{C}$. For experiments involving GAL80 ${ }^{\text {ts }}$, knockdown of Exo84 or expression of Ral ${ }^{D N}$ was achieved at specific developmental stages by raising the temperature to $29^{\circ} \mathrm{C}$ while maintaining them at $18^{\circ} \mathrm{C}$ for the remaining life cycle. For experiments with $d T r p A 1$, flies were maintained at $22^{\circ} \mathrm{C}$, and $0-2$-h-old pupae were collected and transferred to $29^{\circ} \mathrm{C}$ for $72 \mathrm{~h}$ and returned to $22^{\circ} \mathrm{C}$ before eclosion. Fly strains used in this study are listed in Table 1.

\section{Single flight assay}

3-5-d-old flies of either sex were anaesthetized on ice for $\sim 2$ min and then tethered between the head and the thorax using clear nail polish on a thin metal wire. On recovery, they were given an air puff to initiate flight. The duration of flight (up to $15 \mathrm{~min}$ ) was recorded for each fly in batches of 5-10 flies. Flight times of individual flies are represented as box plots.

\section{Pupal neuronal culture}

24-48-h-old pupal CNSs were dissected and enzymatically digested with 50 units/ml papain (Sigma-Aldrich) activated by $1.32 \mathrm{~mm}$ cysteine (Sigma-Aldrich). They were then washed with DDM2 ([DMEM/F-12 with GlutaMAX (Gibco) supplemented with 100 units $/ \mathrm{ml}$ penicillinstreptomycin (Gibco), $10 \mu \mathrm{g} / \mathrm{ml}$ Amphotericin B (Gibco), 20 $\mathrm{mM}$ HEPES (Sigma-Aldrich), $50 \mu \mathrm{g} / \mathrm{ml}$ insulin (SigmaAldrich), and $20 \mathrm{ng} / \mathrm{ml}$ progesterone (Sigma-Aldrich)], triturated with a pipette, and plated in $200 \mu \mathrm{l}$ DDM2 for $\sim 4$ CNS per plate coated with $0.1 \mathrm{mg} / \mathrm{ml}$ poly-D-lysine (Sigma-Aldrich). Cultures were incubated in an incubator at $25^{\circ} \mathrm{C}$ with $5 \% \mathrm{CO}_{2}$ for $18-24 \mathrm{~h}$ before imaging.

\section{Live imaging for vesicular release using ANF::GFP}

Pupal cultures washed and imaged in $\mathrm{HL} 3(70 \mathrm{~mm} \mathrm{NaCl}$, $5 \mathrm{~mm} \mathrm{KCl}, 20 \mathrm{~mm} \mathrm{MgCl}_{2}, 10 \mathrm{~mm} \mathrm{NaHCO}_{3}, 5 \mathrm{~mm}$ trehalose, $115 \mathrm{~mm}$ sucrose, $5 \mathrm{~mm}$ HEPES, pH 7.2) with calcium (1.5 $\mathrm{mm})$. Images were taken as a time series on an $X Y$ plane at an interval of $4 \mathrm{~s}$ using a $40 \times$ objective with an NA of 1.4 on an Olympus FV1000 inverted confocal microscope (Olympus Corp.). The raw images were extracted using Fiji (Schindelin et al., 2012), and regions of interest (ROIs) representing cells were selected using the Time Series Analyzer plugin. Percentage $\Delta F / F$ release was calculated as $\left(F_{0}-F_{t}\right) / F_{0} \times 100$, where $F_{t}$ is the fluorescence at time 
Table 1. List of fly strains used

\begin{tabular}{|c|c|c|}
\hline Fly line & Description & Source \\
\hline elav ${ }^{\mathrm{C} 155}$ GAL4 & Pan-neuronal driver & BDSC 458 \\
\hline OK371-GAL4 & Glutamatergic driver & BDSC 26160 \\
\hline TH-GAL4 & Dopaminergic driver & Friggi-Grelin et al., $2003 a$ \\
\hline TH-D1 GAL4 & Dopaminergic subset neuron driver & Liu et al., 2012 \\
\hline TH-D' GAL4 & Dopaminergic subset neuron driver & Liu et al., 2012 \\
\hline TH-A GAL4 & Hypoderm specific dopaminergic driver & Liu et al., 2012 \\
\hline TRH GAL4 & Serotonergic driver & Sadaf et al., 2012 \\
\hline tubGAL80 ${ }^{\text {ts }}$ & GAL80 $^{\text {ts }}$ ( 2 copies) under tubulin promoter & McGuire et al., 2003 \\
\hline UAS-ANF::GFP & Rat ANF peptide tagged to GFP & BDSC 7001 \\
\hline UAS-spH & SynaptopHluorin & $\mathrm{Ng}$ et al., 2002 \\
\hline UAS-GCaMP6m & Calcium sensor & BDSC 42748 \\
\hline UAS-dTrpA1 & Temperature sensitive cation channel & BDSC 26263 \\
\hline UAS- $\mathrm{H}_{2} \mathrm{BmRFP}$ & Nuclear RFP & Gift from Boris Egger Langevin et al., 2005 \\
\hline UAS-Shits & Temperature-sensitive Dynamin mutant & Kitamoto, 2001 \\
\hline UAS-Ral ${ }^{\mathrm{DN}}$ & Dominant negative form of Ral & BDSC 32094 \\
\hline UAS-Ral' ${ }^{\mid R}$ & RNAi against Ral & BDSC 29580 \\
\hline UAS-dStim ${ }^{I R}$ & RNAi against dStim & VDRC 47073 \\
\hline UAS-RalWT & Wild-type Ral & Richhariya et al., 2017 \\
\hline UAS-Exo84 ${ }^{I R}$ & RNAi against Exo84 & VDRC 30111 \\
\hline UAS-Exo84 ${ }^{I R}$ (line 2) & RNAi against Exo84 & BDSC 28712 \\
\hline UAS-Sec5 $5^{\mathrm{IR}}$ & RNAi against Sec5 & VDRC 28874 \\
\hline UAS-Sec6 $6^{\mathrm{IR}}$ & RNAi against Sec6 & VDRC 105836 \\
\hline UAS-Sec6 ${ }^{\mathrm{IR}}$ (line 2) & RNAi against Sec6 & VDRC 22079 \\
\hline
\end{tabular}

$t$ and $F_{0}$ is baseline fluorescence corresponding to the average fluorescence over the first 10 frames. The area under the curve from these response curves was calculated from 300 to $900 \mathrm{~s}$ using Microsoft Excel (Microsoft) and implementing the trapezoidal rule (Nedelman and Gibiansky, 1996; Qin et al., 2009) where

$$
A U C=\int_{t 1}^{t 2} \frac{\Delta F}{F}(t) \partial t
$$

Here, $t_{1}=300 \mathrm{~s}$ and $t_{2}=900 \mathrm{~s}$, and this accounts for both positive and negative AUC measurements. For experiments involving UAS-Shits, a heated microscope stage was used.

\section{Ex vivo synaptopHluorin imaging from pupal brains}

Brains were dissected in larval hemolymph-like saline (HL3) consisting of $108 \mathrm{~mm} \mathrm{NaCl}, 5 \mathrm{~mm} \mathrm{KCl,} 2 \mathrm{~mm} \mathrm{CaCl}_{2}$, $8.2 \mathrm{~mm} \mathrm{MgCl}_{2}, 4 \mathrm{~mm} \mathrm{NaHCO}, 1 \mathrm{~mm} \mathrm{NaH}_{2} \mathrm{PO}_{4}, 5 \mathrm{~mm}$ trehalose, $10 \mathrm{~mm}$ sucrose, $5 \mathrm{~mm}$ Tris, $\mathrm{pH} 7.5$, and filtered through a 0.2- $\mu \mathrm{m}$ filter (Makos et al., 2010). Dissected brains expressing synaptopHluorin $(\mathrm{spH})$ were embedded in $0.2 \%$ low-melt agarose and bathed in HL3. Images were taken as a time series across depth at an interval of 4 s using a $10 \times$ objective with an NA of 0.4 on a Leica SP5 confocal microscope using a resonant scanner allowing for fast scan speeds. Images were analyzed using Fiji. The $X Y Z$ time series was projected along $Z$ using the maximum-intensity function on Fiji. ROls were selected using the Time Series Analyser plugin. $\Delta F / F$ was calculated as $\left(F_{t}-F_{0}\right) / F_{0}$, where $F_{0}$ is baseline fluorescence corresponding to the average fluorescence over the first 10 frames and $F_{t}$ is the fluorescence at time $t$. Area under the curve was calculated from 60 to $300 \mathrm{~s}$ for salineinduced release and from 300 to $600 \mathrm{~s}$ for evoked release by standard methods invoking the trapezoid rule as mentioned above using Microsoft Excel.

\section{Data representation and statistics}

All flight data and quantifications of vesicular release are represented as box plots using BoxplotR (Spitzer et al., 2014), where horizontal lines represent medians, crosses indicate means, box limits indicate 25th and 75th percentiles, whiskers extend 1.5 times the interquartile range from the 25th and 75 th percentiles, individual data points are represented as open circles, and the numbers below represent the $n$ number for each box. Traces from live-imaging experiments represent means ( \pm standard error of means) from all cells or ROls.

Comparisons between two samples were performed using the two-tailed Student's $t$ test. If more than two conditions were involved, one-way ANOVA followed by Tukey's test was used. All statistical tests were performed using Origin 8.0 software (Micro Cal). Statistical tests and exact $p$-values used in each figure are listed in Table 1-1.

\section{Results}

\section{Exocyst function during pupal development is required for adult flight maintenance}

Inhibition or knockdown of the small GTPase Ral in pupal neurons leads to significant flight deficits in adult flies (Richhariya et al., 2017). To test if Ral function in pupal neurons is exocyst dependent, three components of the exocyst complex, Sec5, Sec6, and Exo84 (Finger and Novick, 1998; Guo et al., 1999) were independently knocked down by pan-neuronal expression of RNA interference constructs with the GAL4 driver Elav ${ }^{C 155}$ (Lin and Goodman, 1994). Knockdown of each of the three exocyst components resulted in significantly shortened flight durations compared to the corresponding RNAi controls 

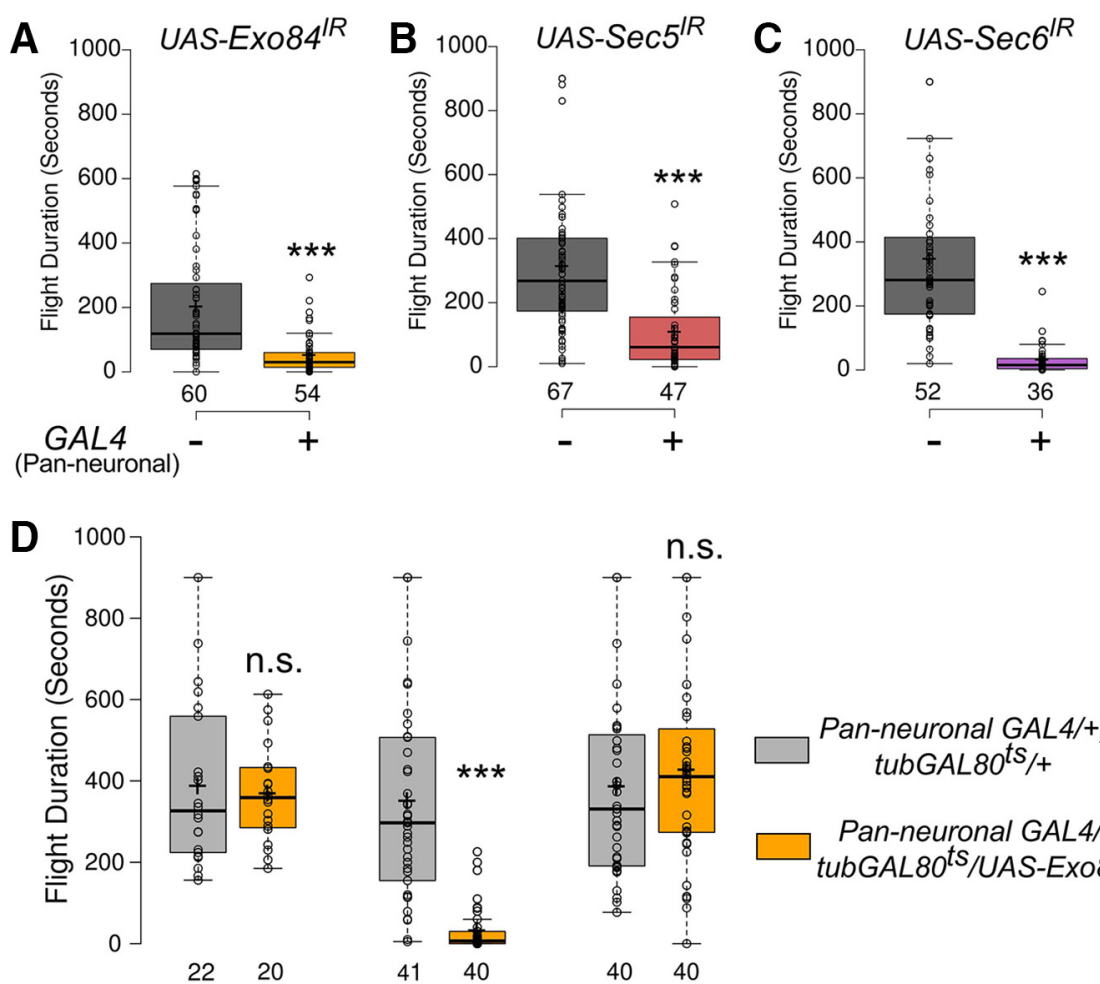

n.s.

Pupal

Adult

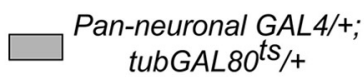

Pan-neuronal GAL4/+; tubGAL80 ${ }^{t S} /$ UAS-Exo84 ${ }^{I R}$

Figure 1. Exocyst components are required in pupal neurons for maintaining the duration of adult flight bouts (refer to Figs. 1-1 and 1-2 and Table 1-1). A-C, Box plots represent durations of flight bouts in flies from the indicated genotypes measured by the single flight assay. $\boldsymbol{D}$, Box plots represent durations of flight bouts in flies with knockdown of Exo84 in neurons during the indicated stages of development. In the box plots, horizontal lines represent medians, crosses indicate means, box limits indicate 25th and 75th percentiles, whiskers extend 1.5 times the interquartile range from the 25th and 75th percentiles, individual data points are represented as open circles, and the numbers below represent the $\mathrm{n}$ number for each box. $* * *, \mathrm{p}<0.001$, n.s., not significant at $p<0.05$ by two-tailed Student's t test. For exact $p$-values, refer to Table 1-1.

(Fig. 1A-C). This indicates a role for the exocyst complex in flight, as none of the RNAis used have any predicted off-targets (Dietzl et al., 2007). Furthermore, significant flight defects were also obtained with independent RNAi lines for Exo84 and Sec6 (Fig 1-1A,B).

The temporal requirement of the exocyst complex for flight was investigated by knockdown of Exo84, as a proxy for the complex, at different developmental stages using the TARGET system (McGuire et al., 2004). Knockdown in the pupal stage alone resulted in flight deficits equivalent to those observed by knockdown throughout development, suggesting that Ex084 expression is exclusively required during pupal development for maturation of the flight circuit. Indeed, Exo84 knockdown exclusively in either the larval or adult stage did not alter flight durations significantly from the respective controls (Figs. $1 D$ and $1-1 C, D)$. This temporal requirement of Exo84 in the context of flight coincides with that of Ral and SOCE observed earlier (Richhariya et al., 2017). Therefore, regulation of exocyst components by SOCE was tested next. There was no change in mRNA levels of the three exocyst components, Exo84, Sec5, and Sec6, in pupal neurons with knockdown of a core SOCE component, the ER-Ca ${ }^{2+}$ sensor, dStim, when Ral levels were found to be reduced (Richhariya et al., 2017; Fig. 1-2A-D). These data demon- strate a requirement for SOCE, Ral, and ExO84 in pupal neurons for adult flight maintenance and suggest that SOCE modulates exocyst-dependent vesicular release in maturing pupal neurons, most likely by regulating Ral expression as identified earlier (Richhariya et al., 2017).

\section{Ral functions downstream of dStim to mediate vesicular release in pupal neurons}

To measure vesicular release in pupal neurons, we used the rat atrial natriuretic peptide tagged with emerald GFP (ANF::GFP). ANF::GFP is recognized by the Drosophila protein-sorting machinery, and its expression is detected in all neurons after embryonic stage 17 when driven by a pan-neuronal GAL4 (Rao et al., 2001). Vesicular release by ANF::GFP expression has been measured from peptidergic (Kula et al., 2006) and nonpeptidergic (Levitan et al., 2007; Liu et al., 2012) neurons in vivo. The vesicular release assay in pupal neurons was standardized by expression of a temperature-sensitive dynamin mutant, Shibire $^{t s}\left(S h i^{t s}{ }^{1}\right)$, that reversibly blocks vesicular release in Drosophila neurons at $29^{\circ} \mathrm{C}$ but not at $22^{\circ} \mathrm{C}$ (Kitamoto, 2001) and can also block peptide release at the restrictive temperature (Wong et al., 2015). In neurons expressing both ANF::GFP and $\mathrm{Shi}^{i s i}$, depolarization by $\mathrm{KCl}$ at $22^{\circ} \mathrm{C}$ resulted in a decrease in ANF::GFP intensity at the soma 

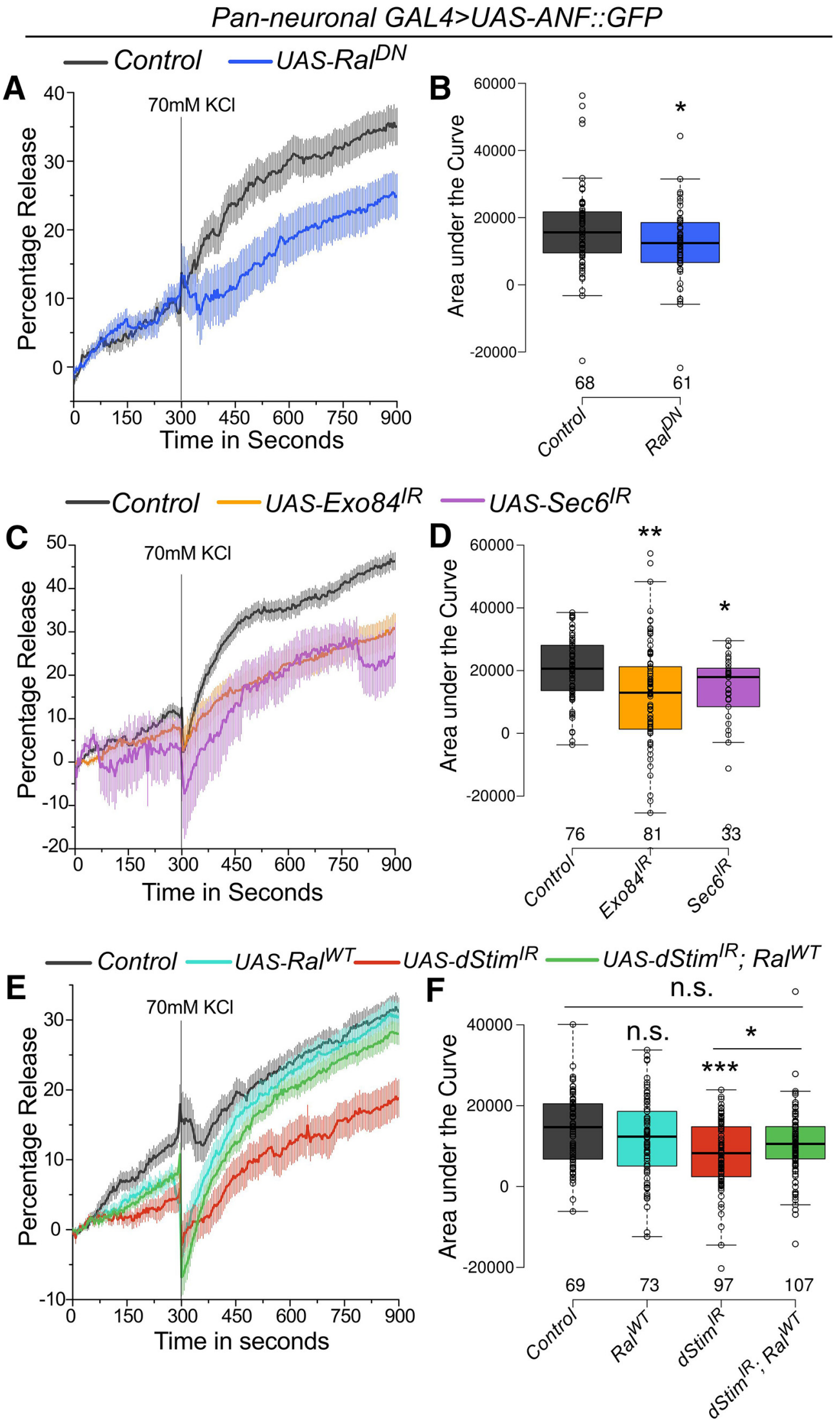

Figure 2. dStim regulates vesicular release in pupal neurons through Ral (refer to Fig. 2-1 and Table 1-1). A, C, E, Traces represent release of ANF::GFP, estimated by reduction in GFP fluorescence, on depolarization with $\mathrm{KCl}$. Lines represent means and the error 
continued

bars, standard error of means, from cells as mentioned in the box plots on the right. Point of $\mathrm{KCl}$ addition is indicated with a line. $\boldsymbol{B}, \boldsymbol{D}, \boldsymbol{F}$, Amount of release quantified as area under the curve from 300 to $900 \mathrm{~s}$ is represented as box plots for the indicated genotypes. Box plots symbols are as described in Fig. 1. Numbers below each box represent number of cells analyzed from at least three different culture dishes. $*, p<0.05, * *, p<0.01, * * *, p<0.001$, n.s., not significant at $p<0.05$ by two-tailed Student's $t$ test (for $\boldsymbol{A}$ ) or one-way ANOVA followed by post hoc Tukey's test (for $\boldsymbol{D}$ and $\boldsymbol{F}$ ). All comparisons for significance were with the control values except where marked by a horizontal line. For exact $p$-values, refer to Table 1-1.

of cultured neurons over time (Fig. 2-1A-C). To rule out effects of elevated temperature on neuronal activity-mediated release (Tomchik, 2013), or on GFP fluorescence, we performed the same experiment without $S h i^{t s 1}$ at $29^{\circ} \mathrm{C}$ and observed release comparable to that at the permissive temperature of $22^{\circ} \mathrm{C}$ with $\mathrm{Shi}^{\mathrm{ts} 1}$ (Fig. 2-1B,C). The small rise observed just before stimulation could be either basal release or possibly an artifact of photobleaching, as it was similar under all conditions (Fig. 2-1B,D). Furthermore, the drop in intensity of ANF::GFP was specific to a depolarization stimulus and not due to osmotic shock, because replacement of $\mathrm{KCl}$ with $\mathrm{NaCl}$ (at the same concentration as $\mathrm{KCl}$ ) did not result in reduction of ANF::GFP intensity above baseline levels (Fig. 2-1C,D). Thus, we interpret reduction in GFP intensity after $\mathrm{KCl}$ addition as vesicular release from the soma due to depolarization.
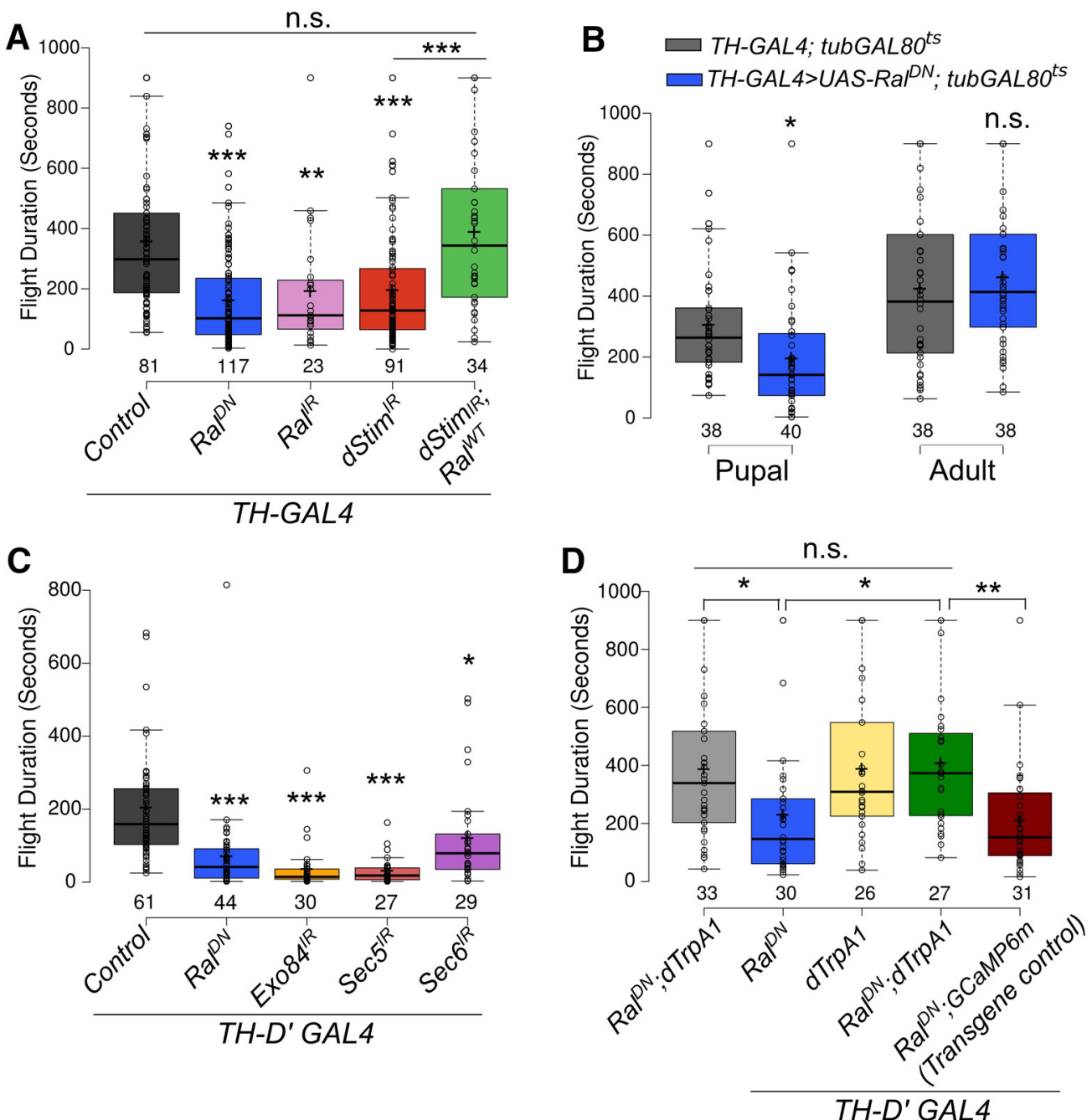

Figure 3. Extended flight bout durations in adults requires Ral and exocyst function in pupal dopaminergic neurons (refer to Fig. 3-1 and Table 1-1). A, C, Box plots represent flight bout durations of flies from the indicated genotypes measured by the single flight assay. $\boldsymbol{B}$, Box plots represent flight bout durations of flies with expression of a dominant negative mutant of Ral (Ral ${ }^{D N}$ ) in dopaminergic neurons during the indicated stages of development. $\boldsymbol{D}$, Box plots represent flight bout durations of flies from the indicated genotypes that were grown at $22^{\circ} \mathrm{C}$ and transferred to $29^{\circ} \mathrm{C}$ from 0 to $72 \mathrm{~h}$ after Puparium formation for activation of $d T r p A 1$. Box plot symbols are as described in Fig. 1. $*, p<0.05, * *, p<0.01, * * *, p<0.001$, n.s., not significant at $p<0.05$ by two-tailed Student's $t$ test (for $\boldsymbol{B}$ ) or one-way ANOVA followed by post hoc Tukey's test (for $\boldsymbol{A}, \boldsymbol{C}$, and $\boldsymbol{D}$ ). All comparisons for significance were with the control values except where marked by a horizontal line. For exact $p$-values, refer to Table 1-1. 
A

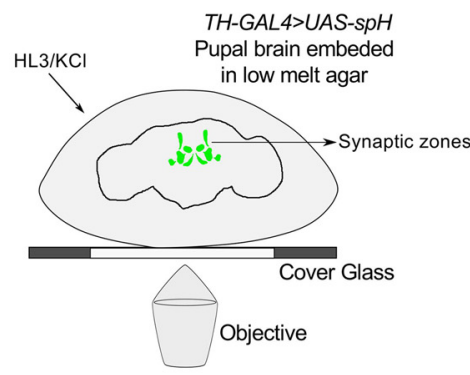

B

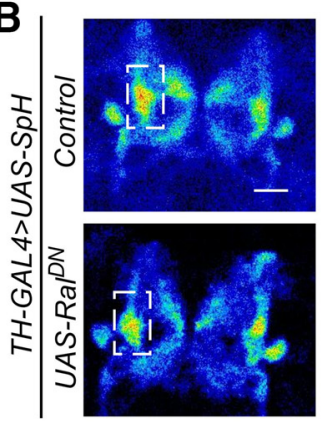

$0 \mathrm{~s} \stackrel{\mathrm{HL} 3}{120 \mathrm{~s}} \mathrm{KCl}$
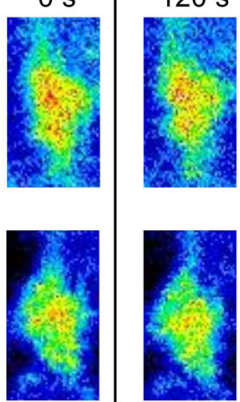

$360 \mathrm{~s}$

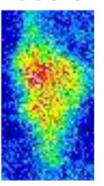

$600 \mathrm{~s}$
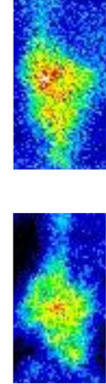

TH-GAL4>UAS-spH; UAS-
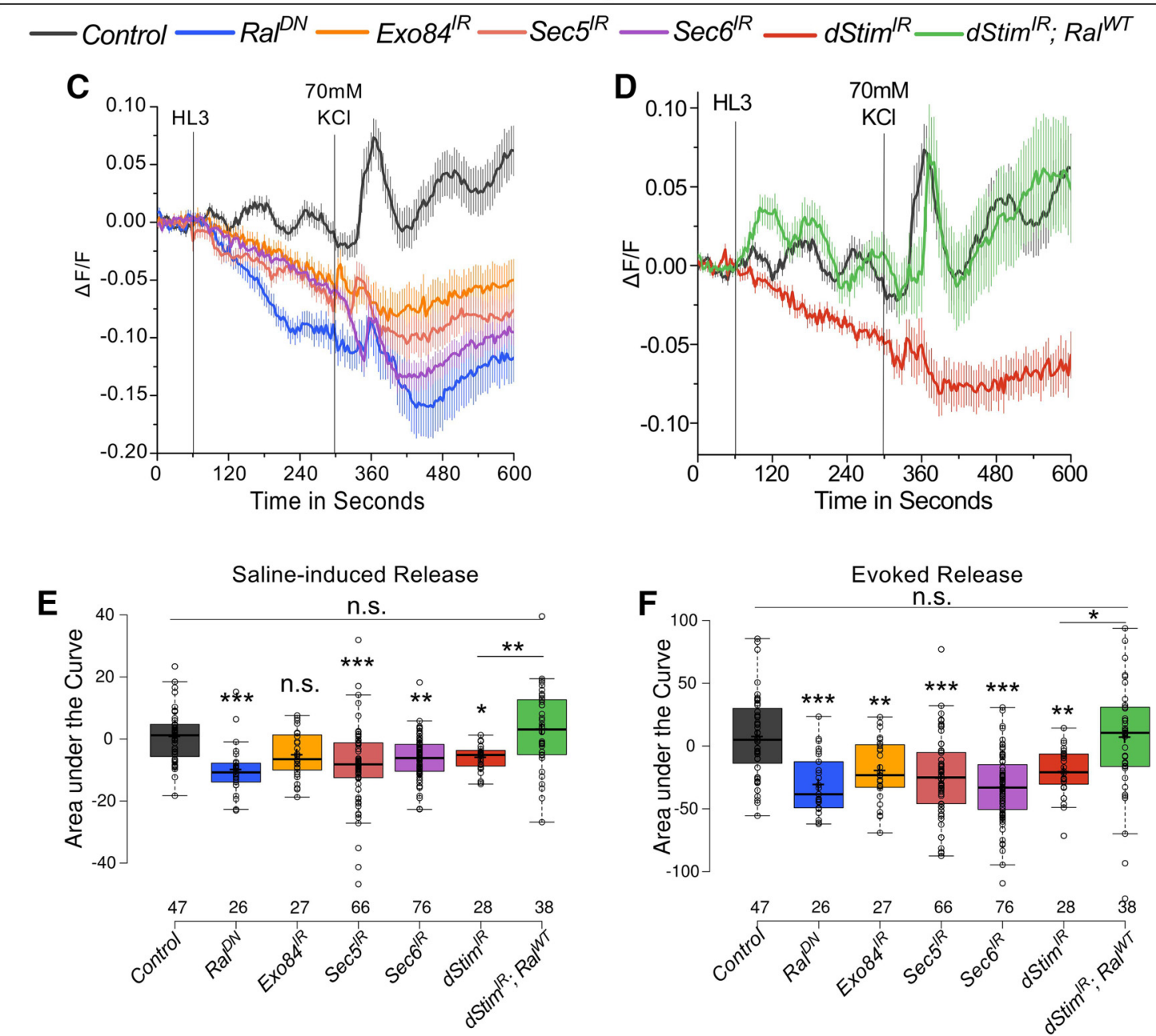

Figure 4. dStim regulates evoked synaptic release from pupal dopaminergic neurons through Ral (Refer to Fig. 4-1 and Table 1-1). $\boldsymbol{A}$, Schematic representation of the experimental setup used to image vesicular release from pupal brains. $\boldsymbol{B}$, Representative images of central regions of pupal brains expressing spH in dopaminergic neurons. Boxed images on the right were obtained by zooming into the inset (white box in the images on the left) at the indicated time points of the time series. $\boldsymbol{C}, \boldsymbol{D}$, Traces represent average ( \pm SEM) change in fluorescence of $\mathrm{spH}$ over time from brains of the indicated genotypes. Points of addition of HL3 and KCl are denoted by vertical lines. $\boldsymbol{E}, \boldsymbol{F}$, Amount of release quantified as area under the curve from 60 to $300 \mathrm{~s}$ (E-Saline-induced) and 300 to $600 \mathrm{~s}$ ( $\mathrm{F}-\mathrm{KCl}-$ evoked) from traces in $\boldsymbol{C}$ and $\boldsymbol{D}$ is represented as box plots for the indicated genotypes. Box plot symbols are as described in Fig. 1. Numbers below the boxes represent number of ROls in which fluorescence changes were measured. They were obtained from a minimum of five brains per genotype. $*, p<0.05, * *, p<0.01$, ***, $p<0.001$, n.s., not significant at $p<0.05$ by one-way ANOVA followed by post hoc Tukey's test. All comparisons for significance were with the control values except where marked by a horizontal line. For exact $p$-values, refer to Table 1-1. 
Blocking vesicular recycling by subjecting neurons expressing $S h i^{\text {ts } 1}$ to the restrictive temperature $\left(29^{\circ} \mathrm{C}\right)$ while imaging led to a significant reduction in release of ANF:: GFP compared to the permissive temperature (Fig. $2-1 A-C)$, validating this assay for assessing vesicular release in primary cultures of pupal neurons.

Inhibiting Ral function in cultured pupal neurons by expression of a dominant-negative form of Ral, $R a l^{D N}$, led to a significant reduction in release of ANF::GFP (Fig. $2 A, B)$. A similar reduction in release was observed on knockdown of either Exo84 or Sec6 (Fig. 2C,D), which correlates with the strong flight defects observed on their knockdown (Fig. 1A,C). Knockdown of an essential neuronal SOCE component, dStim, also led to reduction in ANF::GFP release, as predicted from previous data demonstrating that Ral expression in pupal neurons requires SOCE (Richhariya et al., 2017, Fig. 2E,F). Furthermore, reduced release of ANF::GFP by dStim knockdown could be rescued by overexpressing $R a I^{W T}$ (Fig. 2E,F), indicating that Ral function is downstream of SOCE in mediating vesicular release in pupal neurons.

\section{Ral function in pupal dopaminergic neurons is required for adult flight maintenance}

Next, we tested the spatio-temporal requirement for Ral in previously identified neuronal subsets where loss of SOCE is known to affect the maintenance of flight bouts. These include dopaminergic (Pathak et al., 2015) and glutamatergic (Venkiteswaran and Hasan, 2009) neurons. Blocking Ral function either in all glutamatergic neurons by the OK371-GAL4 (Mahr and Aberle, 2006) or in the motor neurons using the OK6-GAL4 (Sanyal, 2009) resulted in significantly reduced flight durations (Fig. 3-1A,B). Similarly, reducing either $\mathrm{Ral}$ levels or function in dopaminergic cells, with TH-GAL4 (Friggi-Grelin et al., 2003a), resulted in significantly reduced flight durations that were comparable to flight deficits observed by knockdown of dStim (Fig. 3A). Importantly, the flight deficits observed on dStim knockdown were rescued to control levels by restoring Ral function, when $R a l^{W T}$ was overexpressed in this background (Fig. 3A). Ral knockdown exclusively during the pupal stage, but not in the adult stage, resulted in flight durations significantly lower than those of control flies (Figs. $3 B$ and 3-1C,D).

Because TH-GAL4 expresses in both neuronal and non-neuronal cells (Friggi-Grelin et al., 2003b), we further refined the spatial requirement of Ral for flight using GAL4 drivers that mark dopaminergic cell subsets. Significantly shortened flight durations were observed on reducing Ral function with the neuronal-specific $T H-D^{\prime}$ (Fig. 3C) and TH-D1 (Fig. 3-1F) GAL4s (Liu et al., 2012; Pathak et al., 2015). However, attenuating Ral function in hypodermal cells with TH-A GAL4 (Liu et al., 2012) did not significantly alter the duration of flight (Fig 3-1G). Blocking Ral function in serotonergic neurons with the TRH-GAL4 also did not affect flight duration (Fig. 3-1E). Thus, Ral is required in pupal dopaminergic neurons for a functional adult flight circuit. These data are in agreement with previous findings demonstrating that loss of SOCE by inhibition of

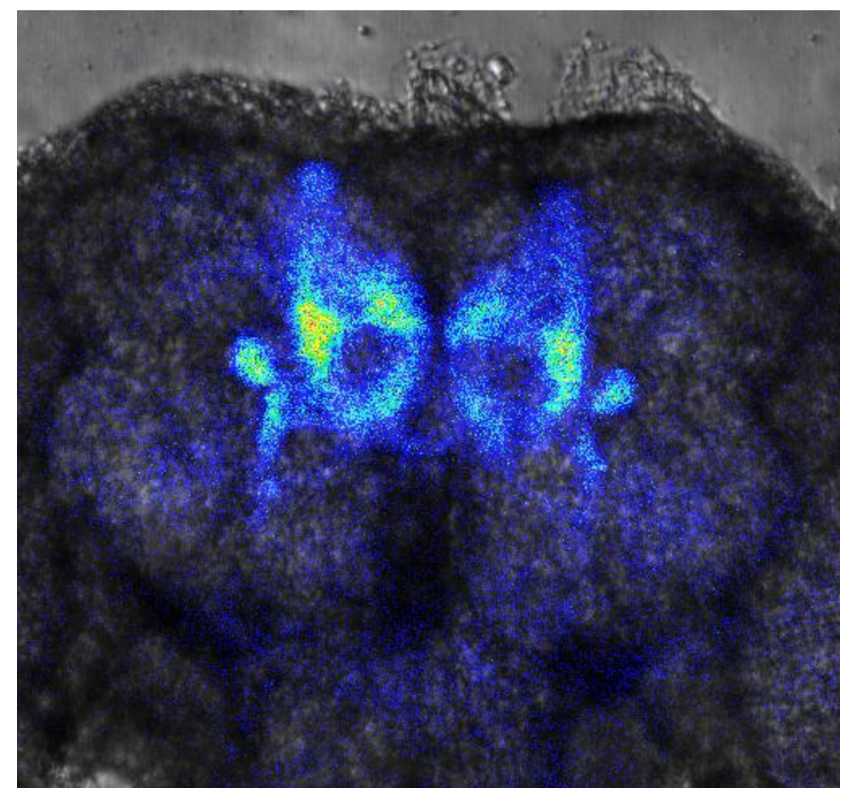

Video 1. Visualizing synaptic release from dopaminergic neurons. Changes in fluorescence of $\mathrm{spH}$ driven by the TH-GAL4 indicative of synaptic release from dopaminergic neurons in the mushroom body. Gray flash indicates addition of HL3 (mock); red flash indicates addition of $70 \mathrm{~mm} \mathrm{KCl}$. [View online]

dOrai in similar subsets of pupal dopaminergic neurons impairs flight in adult Drosophila (Pathak et al., 2015).

Knockdown of the exocyst components, Exo84, Sec5, and Sec6, in $T H-D^{\prime} G A L 4$-marked dopaminergic neurons also resulted in flight deficits (Fig. 3C). Importantly, the flight deficits observed on reducing Ral function in dopaminergic neurons could be rescued by expression of the heat-activated cation channel $d T r p A 1$ in $T H-D^{\prime}$ marked neurons in pupae (Fig. 3D). Expression of a neutral transgene, GCaMP6m, had no effect on the fight deficit shown by animals expressing $R a l^{D N}$ in $T H-D^{\prime}$-marked neurons (Fig 3D). dTrpA1 enhances neuronal activity (Hamada et al., 2008) and thus, possibly, the extent of vesicular release in pupal dopaminergic neurons. This was tested next.

\section{dStim regulates synaptic vesicle release from pupal dopaminergic neurons through $\mathrm{Ral}$}

Vesicular release from neurons can occur either through small synaptic vesicles (SSVs) or large dense core vesicles (LDCVs). SSVs are small, clear vesicles that primarily carry neurotransmitters whereas LDCVs are large, granular vesicles that transport neuropeptides, hormones and aminergic neurotransmitters (Park and Kim, 2009). Mammalian Ral colocalizes with both SSVs (Volknandt et al., 1993) and LDCVs (De Leeuw et al., 1999) and hence, regulation by Ral of both classes of vesicles is possible in Drosophila. The assay with ANF::GFP in cultured neurons (Figs. 2 and 2-1) most likely assayed for release from LDCVs at the soma, and although such vesicles can corelease a monoamine neurotransmitter like dopamine (Nusbaum et al., 2017), it would not test the ability of Ral to affect neurotransmitter release from SSVs. To measure release from SSVs at synaptic release sites in the maturing pupal 


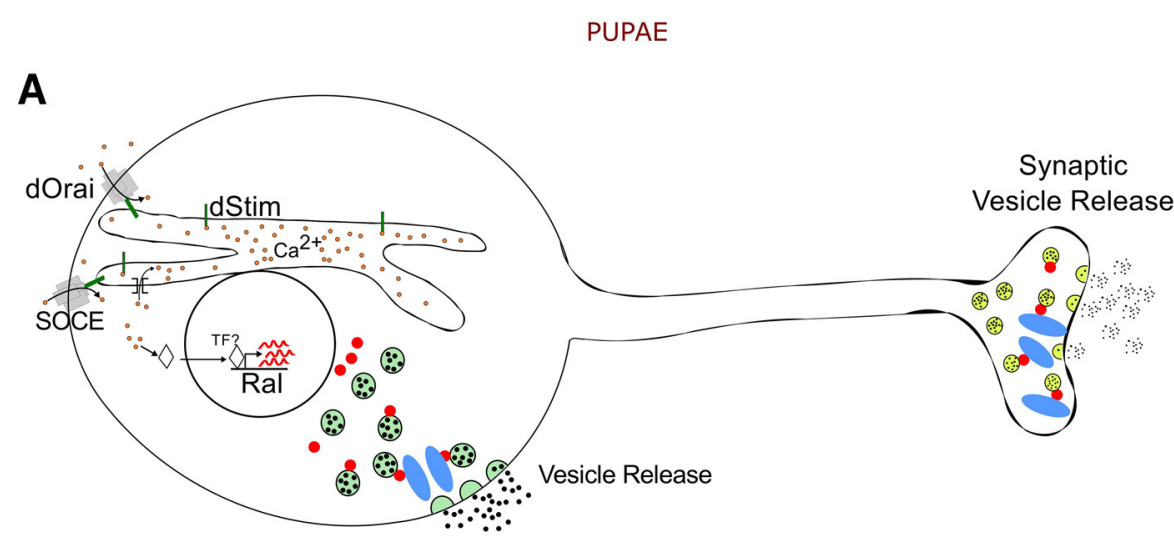

ADULTS
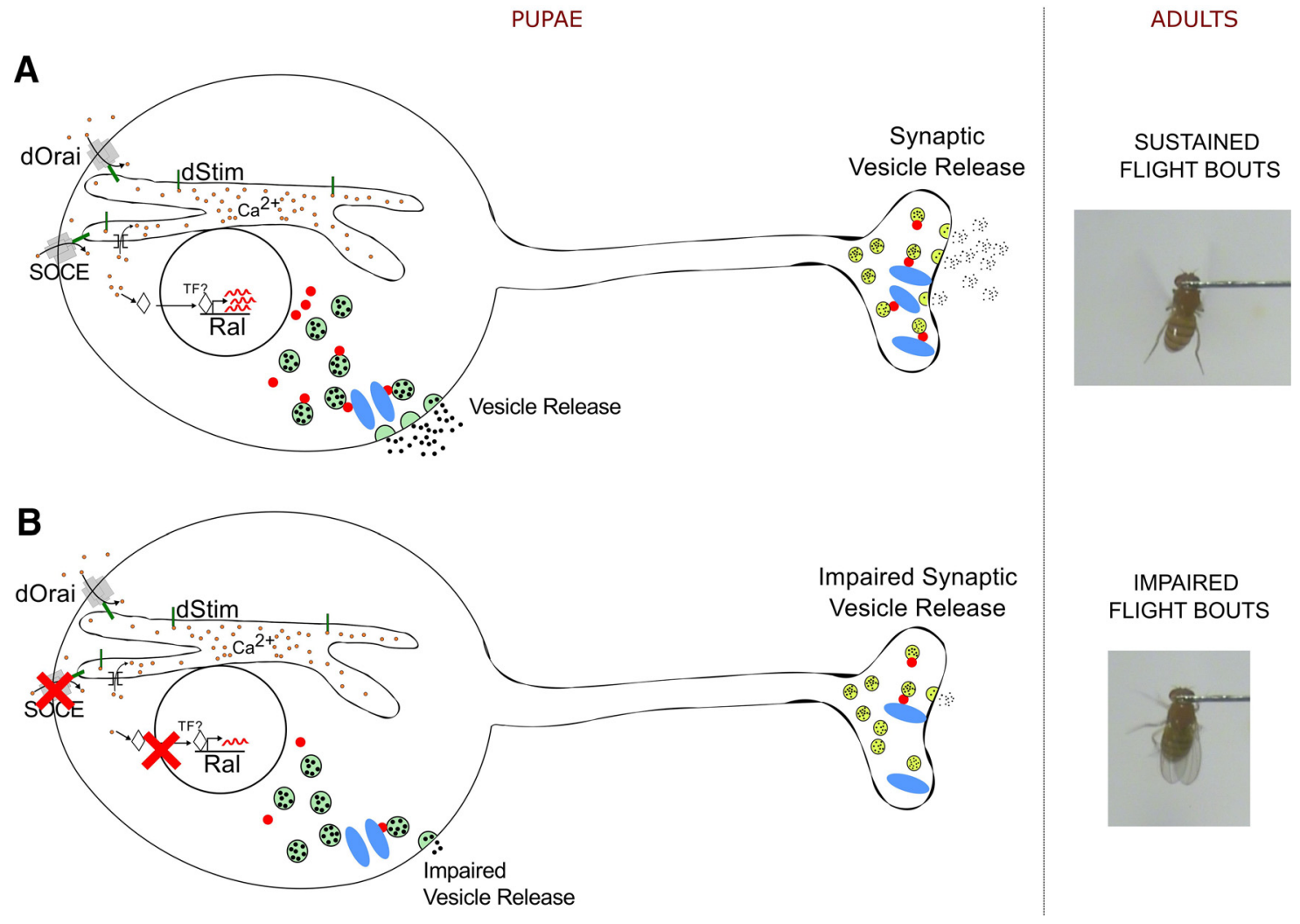

IMPAIRED

FLIGHT BOUTS

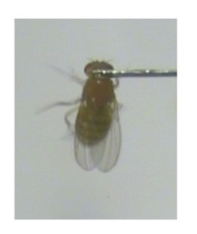

\section{LDCVs SSVs - Ral Exocyst Complex ][SERCA}

Figure 5. Vesicle release regulated by SOCE, Ral, and the exocyst in pupal neurons regulates flight in adults. $\boldsymbol{A}$, Cartoon representation of a pupal neuron where SOCE regulates Ral expression. Ral is required for tagging secretory vesicles toward the exocyst complex, thus marking them for both somatic and synaptic release. Such regulated vesicular release of dopamine from pupal neurons appears essential for maturation of a neural circuit required in adults for maintaining the duration of flight bouts. $\boldsymbol{B}$, In conditions of dStim knockdown, when SOCE is attenuated, Ral levels are reduced, and this in turn has a negative impact on vesicular release in dopaminergic neurons. Consequently, flight bout durations in adult flies are also reduced.

brain, we used spH, a pH-sensitive GFP, that localizes to synaptic vesicles and whose fluorescence is quenched in acidic conditions but fluoresces on fusion of the vesicle with the pre-synaptic membrane (Miesenböck et al., 1998). SSV release was important to assess, because SOCE-regulated expression of TH, a dopaminesynthesizing enzyme, in pupal stages is required for adult flight (Pathak et al., 2015), suggesting that formation of appropriate functional connectivity between central dopaminergic neurons and their postsynaptic targets requires dopamine release. We hypothesized that SOCE and Raldependent exocyst function could be a mechanism underlying such dopamine release in developing synapses of the pupal brain.

Synaptic release from dopaminergic neurons in pupae was visualized in ex vivo preparations of $48-72-\mathrm{h}$ old pupal brains expressing UAS-spH (Ng et al., 2002) using TH-GAL4 (Fig. 4A). The TH-GAL4 marks synaptic zones in parts of the mushroom body (MB) viz. the $\alpha$ and $\alpha^{\prime}$ vertical lobes, upper stalk, lower stalk and junction, and the distal heel and peduncle deriving from the PPL1 neurons among others (Mao and Davis, 2009). Thus, synaptic release was measured at maturing synaptic zones of the MB (Fig. 4A). Depolarization by $\mathrm{KCl}$ evoked vesicle release, as evidenced by a visible and quantifiable change in $\mathrm{spH}$ fluorescence (Video 1 and Fig. $4 B-D, F$ ). The amplitude and kinetics of the change in fluorescence observed were similar to what have been observed earlier using $\mathrm{spH}$ in mammalian (Burrone et al., 2007) and Drosophila neurons (Slawson et al., 2014). Interestingly, addition of hemolymph-like saline (HL3) caused a measurable level of synaptic release at the MB synaptic zones even without $\mathrm{KCl}$-induced depolarization (Video 1 and Fig. 4C,E). This saline-induced release could result from basal activity of the endogenous circuit activity, because the recordings were performed from an intact live brain without any inhibitors. Both saline and depolarization evoked release from pupal dopaminergic neurons were severely affected on either, reducing Ral function or knockdown of exocyst components as well as knockdown of dStim (Figs. $4 B-F$ and $4-1 D-F$ ). Importantly, overexpression of wild-type $R a$ in the background of dStim knockdown rescued both saline and $\mathrm{KCl}$ evoked release (Fig. 4D-F). Expression of a neutral transgene, $U A S-H_{2} B m R F P$ in dStim knockdown background, did not 
rescue either kind of release (Fig. 4-1A-C), demonstrating that rescue was indeed because of restoring $R a l$ levels and not insufficient knockdown of dStim caused by expression of multiple transgenes.

\section{Discussion}

Neuronal Ral was recently identified as a regulator of Drosophila flight (Richhariya et al., 2017). In this study, we have identified dopaminergic neurons as a cellular focus for Ral function during flight circuit maturation in pupae. In dopaminergic neurons Ral functions through Ex084, and presumably the exocyst, to regulate synaptic release during pupal development. Moreover, we identify a novel role for the SOCE gene dStim in regulating synaptic vesicular release through positive control of Ral gene expression, identified previously in a screen for SOCE-regulated genes (Richhariya et al., 2017). Importantly, both flight deficits and reduced synaptic vesicular release observed as a consequence of dSTIM knockdown were rescued by Ral over-expression in dopaminergic neurons. These findings support an essential requirement for dopamine release during synapse formation and maturation of the Drosophila flight circuit (Pathak et al., 2015; Fig. 5).

We observed a loss of somatic and synaptic vesicular release on knockdown of dStim, Ral, and the exocyst components tested (Figs. 2 and 4). Because Ral and the exocyst have established roles in regulating pre-synaptic vesicle dynamics and exocytosis (Moskalenko et al., 2002; Wang et al., 2004) and Ral expression is regulated by dStim (Richhariya et al., 2017), we propose that dStim regulates vesicular release via Ral. However, the reduction in vesicular release on dStim knockdown might also be mediated by other factors such as expression levels and densities of ion channels (Voglis and Tavernarakis, 2006) and altered signaling in response to neurotransmitters (Huang and Thathiah, 2015), which have not been tested here. Because Ral almost completely rescues the release defects of dStim knockdown (Figs. 2E,F and $4 E, F)$, we believe that a significant component of dStim mediated vesicular release in pupal dopaminergic neurons is by regulating expression of Ral.

Activity-dependent calcium entry is essential for synaptic release (Südhof, 2012). However, this is the first report where calcium entry through SOCE regulates synaptic release. Our work demonstrates an important distinction between how the two modes of calcium entry regulate synaptic vesicle release, viz., that SOCE-regulated synaptic release is indirect by regulation of Ral expression. Thus, neuromodulators that stimulate SOCE very likely change synaptic function over time scales that are much greater than activity-based synaptic release. We favor the dSTIM/ dOrai mode of SOCE in this context primarily because very similar flight deficits are observed by knockdown of $d O r a i$ and these can also be rescued by overexpression of Ral (Richhariya et al., 2017).

Data in this paper suggest that dStim, by regulation of Ral expression (Richhariya et al., 2017), impacts both spontaneous and evoked synaptic vesicle release in pupal dopaminergic neurons. Neurotransmitter release from SSVs and neuropeptide as well as neurotransmitter re- lease from LDCVs, regulates multiple steps during the development of neural circuits, including synapse formation and maturation (Lochner et al., 2008; Park and Kim, 2009; Tau and Peterson, 2010). Neurotransmitter release during circuit development can affect both synapse formation and strength (Bleckert and Wong, 2011). Moreover, spontaneous release of neurotransmitters, similar to an earlier observation in larval neurons (Choi et al., 2014), could be important for synaptic maturation. The absence of flight deficits by adult-specific knockdown or abrogation of Ral/Exo84 (Richhariya et al., 2017; Figs. $1 D$ and 3B) function agrees with an earlier finding where exocyst function was dispensable for synaptic release from mature neurons (Murthy et al., 2003).

In pupal dopaminergic neurons, Ral-modulated vesicle release is a likely mechanism by which SOCE affects synaptic maturation and thus function of adult flight circuit neurons. Regulation of circadian activity by Ral has been demonstrated in Drosophila (Klose et al., 2016). Our results suggest that such regulation may be initiated by receptor-stimulated SOCE. Moreover, SOCE-regulated Ral expression and vesicle release at presynaptic sites may act as co-incident detectors of neuromodulatory signals that enhance synaptic efficacy and network drive for optimal function of cognate neural circuits in other organisms as well, including vertebrates.

\section{References}

Agrawal N, Venkiteswaran G, Sadaf S, Padmanabhan N, Banerjee S, Hasan G (2010) Inositol 1,4,5-trisphosphate receptor and dSTIM function in Drosophila insulin-producing neurons regulates systemic intracellular calcium homeostasis and flight. J Neurosci 30:1301-1313. CrossRef

Blankenship AG, Feller MB (2010) Mechanisms underlying spontaneous patterned activity in developing neural circuits. Nat Rev Neurosci 11:18-29.

Bleckert A, Wong ROL (2011) Identifying roles for neurotransmission in circuit assembly: insights gained from multiple model systems and experimental approaches. Bioessays 33:61-72. CrossRef

Burrone J, Li Z, Murthy VN (2007) Studying vesicle cycling in presynaptic terminals using the genetically encoded probe synaptopHluorin. Nat Protoc 1:2970-2978. CrossRef

Choi BJ, Imlach WL, Jiao W, Wolfram V, Wu Y, Grbic M, Cela C, Baines RA, Nitabach MN, McCabe BD (2014) Miniature neurotransmission regulates drosophila synaptic structural maturation. Neuron 82:618-634. CrossRef Medline

Consoulas C, Restifo LL, Levine RB (2002) Dendritic remodeling and growth of motoneurons during metamorphosis of Drosophila melanogaster. J Neurosci 22:4906-4917. Medline

De Leeuw HPJC, Wijers-Koster PM, Van Mourik JA, Voorberg $J$ (1999) Small GTP-binding protein RalA associates with WeibelPalade bodies in endothelial cells. Thromb Haemost 82:11771181. Medline

Dietzl G, Chen D, Schnorrer F, Su K-C, Barinova Y, Fellner M, Gasser B, Kinsey K, Oppel S, Scheiblauer S, Couto A, Marra V, Keleman K, Dickson BJ (2007) A genome-wide transgenic RNAi library for conditional gene inactivation in Drosophila. Nature 448:151-156. CrossRef Medline

Feske S (2007) Calcium signalling in lymphocyte activation and disease. Nat Rev Immunol 7:690-702. CrossRef Medline

Finger FP, Novick P (1998) Spatial regulation of exocytosis: lessons from yeast. J Cell Biol

Friggi-Grelin F, Coulom H, Meller M, Gomez D, Hirsh J, Birman S (2003a) Targeted gene expression in Drosophila dopaminergic cells 
using regulatory sequences from tyrosine hydroxylase. J Neurobiol 54:618-627. CrossRef

Friggi-Grelin F, Iché M, Birman S (2003b) Tissue-specific developmental requirements of Drosophila tyrosine hydroxylase isoforms. Genesis 35:175-184. CrossRef

Gentry LR, Martin TD, Reiner DJ, Der CJ (2014) Ral small GTPase signaling and oncogenesis: more than just 15 minutes of fame. Biochim Biophys Acta 1843:2976-2988.

Guo W, Grant A, Novick P (1999) Exo84p is an exocyst protein essential for secretion. J Biol Chem 274:23558-23564. Medline

Hamada FN, Rosenzweig M, Kang K, Pulver SR, Ghezzi A, Jegla TJ, Garrity PA (2008) An internal thermal sensor controlling temperature preference in Drosophila. Nature 454:217-220. CrossRef Medline

Huang Y, Thathiah A (2015) Regulation of neuronal communication by $\mathrm{G}$ protein-coupled receptors. FEBS Lett 589:1607-1619.

Kitamoto T (2001) Conditional modification of behavior in Drosophila by targeted expression of a temperature-sensitive shibire allele in defined neurons. J Neurobiol 47:81-92. CrossRef

Klose M, Duvall LB, Li W, Liang X, Ren C, Steinbach JH, Taghert PH (2016) Functional PDF signaling in the Drosophila circadian neural circuit is gated by Ral A-dependent modulation. Neuron 90:1-14. CrossRef

Kula E, Levitan ES, Pyza E, Rosbash M (2006) PDF cycling in the dorsal protocerebrum of the Drosophila brain is not necessary for circadian clock function. J Biol Rhythms 21:104-117. CrossRef Medline

Lalli G, Hall A (2005) Ral GTPases regulate neurite branching through GAP-43 and the exocyst complex. J Cell Biol 171:857-869. CrossRef Medline

Langevin J, Le Borgne R, Rosenfeld F, Gho M, Schweisguth F, Bellaïche $Y$ (2005) Lethal giant larvae controls the localization of Notch-signaling regulators Numb, neuralized, and Sanpodo in Drosophila sensory-organ precursor cells. Curr Biol 15:955-962. CrossRef Medline

Levitan ES, Lanni F, Shakiryanova D (2007) In vivo imaging of vesicle motion and release at the Drosophila neuromuscular junction. Nat Protoc 2:1117-1125. CrossRef Medline

Li G, Han L, Chou T-C, Fujita Y, Arunachalam L, Xu A, Wong A, Chiew S-K, Wan Q, Wang L, Sugita S (2007) RalA and RalB function as the critical GTP sensors for GTP-dependent exocytosis. J Neurosci 27:190-202. CrossRef Medline

Lin DM, Goodman CS (1994) Ectopic and increased expression of Fasciclin II alters motoneuron growth cone guidance. Neuron 13: 507-523. Medline

Liu Q, Liu S, Kodama L, Driscoll MR, Wu MN (2012) Two dopaminergic neurons signal to the dorsal fan-shaped body to promote wakefulness in Drosophila. Curr Biol 22:2114-2123. CrossRef Medline

Lochner JE, Spangler E, Chavarha M, Jacobs C, McAllister K, Schuttner LC, Scalettar BA (2008) Efficient copackaging and cotransport yields postsynaptic colocalization of neuromodulators associated with synaptic plasticity. Dev Neurobiol 68:1243-1256. CrossRef Medline

Lohmann C (2009) Calcium signaling and the development of specific neuronal connections. Prog Brain Res 175:443-452.

Mahr A, Aberle H (2006) The expression pattern of the Drosophila vesicular glutamate transporter: a marker protein for motoneurons and glutamatergic centers in the brain. Gene Expr Patterns 6:299309. CrossRef Medline

Majewski L, Kuznicki J (2015) SOCE in neurons: signaling or just refilling? Biochim Biophys Acta - 1853:1940-1952.

Makos MA, Han K-A, Heien ML, Ewing AG (2010) Using in vivo electrochemistry to study the physiological effects of cocaine and other stimulants on the Drosophila melanogaster dopamine transporter. ACS Chem Neurosci 1:74-83. CrossRef

Mao Z, Davis R (2009) Eight different types of dopaminergic neurons innervate the Drosophila mushroom body neuropil: anatomical and physiological heterogeneity. Front Neural Circuits 3:5. CrossRef
McGuire SE, Le PT, Osborn AJ, Matsumoto K, Davis RL (2003) Spatiotemporal rescue of memory dysfunction in Drosophila. Science 302:1765-1768. CrossRef Medline

McGuire SE, Mao Z, Davis RL (2004) Spatiotemporal gene expression targeting with the TARGET and gene-switch systems in Drosophila. Sci STKE 2004:pl6. CrossRef Medline

Miesenböck G, De Angelis DA, Rothman JE (1998) Visualizing secretion and synaptic transmission with $\mathrm{pH}$-sensitive green fluorescent proteins. Nature 394:192-195. CrossRef Medline

Moskalenko S, Henry DO, Rosse C, Mirey G, Camonis JH, White MA (2002) The exocyst is a Ral effector complex. Nat Cell Biol 4:6672. CrossRef Medline

Murthy M, Garza D, Scheller RH, Schwarz TL (2003) Mutations in the exocyst component Sec5 disrupt neuronal membrane traffic, but neurotransmitter release persists. Neuron 37:433-447. Medline

Nedelman JR, Gibiansky E (1996) The variance of a better AUC estimator for sparse, destructive sampling toxicokinetics. J Pharm Sci 85:884-886. CrossRef Medline

$\mathrm{Ng} \mathrm{M}$, Roorda RD, Lima SQ, Zemelman BV, Morcillo P, Miesenböck G (2002) Transmission of olfactory information between three populations of neurons in the antennal lobe of the fly. Neuron 36:463-474. Medline

Nusbaum MP, Blitz DM, Marder E (2017) Functional consequences of neuropeptide and small-molecule co-transmission. Nat Rev Neurosci 18:389-403.

Park Y, Kim K-T (2009) Short-term plasticity of small synaptic vesicle (SSV) and large dense-core vesicle (LDCV) exocytosis. Cell Signal 21:1465-1470. CrossRef Medline

Pathak T, Agrawal T, Richhariya S, Sadaf S, Hasan G (2015) Storeoperated calcium entry through orai is required for transcriptional maturation of the flight circuit in Drosophila. J Neurosci 35:1378413799. CrossRef Medline

Polzin A, Shipitsin M, Goi T, Feig LA, Turner TJ (2002) Ral-GTPase influences the regulation of the readily releasable pool of synaptic vesicles. Mol Cell Biol 22:1714-1722. Medline

Prakriya M, Lewis RS (2015) Store-operated calcium channels. Physiol Rev 95:1383-1436. CrossRef Medline

Qin L, Liu Y, Wang J, Li S, Sato Y (2009) Neural and behaviora discrimination of sound duration by cats. J Neurosci 29:1565015659. CrossRef Medline

Rao S, Lang C, Levitan ES, Deitcher DL (2001) Fast track: visualization of neuropeptide expression, transport, and exocytosis in Drosophila melanogaster. J Neurobiol 49:159-172. CrossRef

Richhariya S, Jayakumar S, Abruzzi K, Rosbash M, Hasan G (2017) A pupal transcriptomic screen identifies Ral as a target of storeoperated calcium entry in Drosophila neurons. Sci Rep 7:42586. CrossRef Medline

Rosenberg SS, Spitzer NC (2011) Calcium signaling in neuronal development. Cold Spring Harb Perspect Biol 3:a004259. CrossRef Medline

Sadaf S, Birman S, Hasan G (2012) Synaptic activity in serotonergic neurons is required for air-puff stimulated flight in Drosophila melanogaster. PLoS One 7:e46405. CrossRef

Sanyal S (2009) Genomic mapping and expression patterns of C380, OK6 and D42 enhancer trap lines in the larval nervous system of Drosophila. Gene Expr Patterns 9:371-380. CrossRef Medline

Schindelin J, et al. (2012) Fiji: an open source platform for biological image analysis. Nat Methods 9:676-682. CrossRef Medline

Slawson JB, Kuklin EA, Mukherjee K, Pírez N, Donelson NC, Griffith LC (2014) Regulation of dopamine release by CASK- $\beta$ modulates locomotor initiation in Drosophila melanogaster. Front Behav Neurosci 8:394. CrossRef Medline

Somasundaram A, Shum AK, McBride HJ, Kessler JA, Feske S, Miller RJ, Prakriya M (2014) Store-operated CRAC channels regulate gene expression and proliferation in neural progenitor cells. $J$ Neurosci 34:9107-9123. CrossRef Medline

Spitzer M, Wildenhain J, Rappsilber J, Tyers M (2014) BoxPlotR: a web tool for generation of box plots. Nat Methods 11:121-122. CrossRef Medline 
Südhof TC (2012) Calcium control of neurotransmitter release. Cold Spring Harb Perspect Biol 4:a011353. CrossRef Medline

Tau GZ, Peterson BS (2010) Normal development of brain circuits. Neuropsychopharmacol Rev 35:147-168. CrossRef Medline

Teodoro RO, Pekkurnaz G, Nasser A, Higashi-Kovtun ME, Balakireva M, McLachlan IG, Camonis J, Schwarz TL (2013) Ral mediates activity-dependent growth of postsynaptic membranes via recruitment of the exocyst. EMBO J 32:2039-2055. CrossRef Medline

Tissot M, Stocker RF (2000) Metamorphosis in Drosophila and other insects: the fate of neurons throughout the stages. Prog Neurobiol 62:89-111.

Tomchik SM (2013) Dopaminergic neurons encode a distributed, asymmetric representation of temperature in Drosophila. J Neurosci 33:2166-2176. CrossRef Medline

Truman JW (1990) Metamorphosis of the central nervous system of Drosophila. J Neurobiol 21:1072-1084. CrossRef Medline
Truman JW, Bate M (1988) Spatial and temporal patterns of neurogenesis in the central nervous system of Drosophila melanogaster. Dev Biol 125:145-157. Medline

Venkiteswaran G, Hasan G (2009) Intracellular Ca2+ signaling and store-operated $\mathrm{Ca} 2+$ entry are required in Drosophila neurons for flight. Proc Natl Acad Sci U S A 106:10326-10331. CrossRef Medline Voglis G, Tavernarakis N (2006) The role of synaptic ion channels in synaptic plasticity. EMBO Rep 7:1104-1110. CrossRef Medline

Volknandt W, Pevsne J, Elferink LA, Scheller RH (1993) Association of three small GTP-binding proteins with cholinergic synaptic vesicles. FEBS Lett 317:53-56. Medline

Wang L, Li G, Sugita S (2004) RalA-exocyst interaction mediates GTP-dependent exocytosis. J Biol Chem 279:19875-19881. CrossRef Medline

Wong MY, Cavolo SL, Levitan ES (2015) Synaptic neuropeptide release by dynamin-dependent partial release from circulating vesicles. Mol Biol Cell 26:2466-2474. CrossRef Medline 